\title{
Teachers' Perception and Factors Limiting the use of High-Tech Assistive Technology in Special Education Schools in North- West Nigeria
}

\author{
Emeka Joshua Chukwuemeka \\ Department of Educational Technology Federal University of Technology, Minna, Niger State, \\ Nigeria \\ ORCID: 0000-0002-1985-8002 \\ Dominic Samaila \\ Department of Educational Technology Federal University of Technology, Minna, Niger State, \\ Nigeria \\ ORCID: 0000-0002-5684-9332
}

Received: 7 Aug 2019

Accepted: 3 Nov 2019

Published: 14 Nov 2019

\begin{abstract}
The study investigated teachers' perception and factors limiting the use of high-tech assistive technologies resources in special education schools in North-West Nigeria. The study adopted a descriptive survey design using a questionnaire to sought data from 120 respondents who were drawn using a multi-stage sampling technique from special education schools within the region. Three research questions were raised to guide the study. The questionnaire was subjected to expert validation and reliability was established through a pilot study using 20 teachers from two special education schools within the study area, but not part of the sampled schools. The reliability coefficient of 0.81 was obtained for the questionnaire using the Cronbach Alpha formula. The data collected were analyzed using percentage, mean and standard deviation. Findings revealed that teachers do not use high-tech assistive devices regularly to teach students with physical disabilities. However, teachers perceived positively that there are great benefits to the use of these resources. It was recommended among others that both government and other stakeholders should organize workshop, seminars and other capacity building training regularly for teachers as means of updating their knowledge and skills in the use of assistive devices considering the dynamic nature of special education technology.
\end{abstract}

Keywords: assistive technology, high-tech, utilization, perception, special education, limiting factors

\section{INTRODUCTION}

It is an established fact that no nation can develop above its educational standard. For this reason, the nation of Nigeria has emphasized the need for better education service delivery for all. In order to achieve this, there is a need for extensive integration of Information and Communication-based Technologies (ICT) as an integral part of the teaching and learning process as well as other educational needs. For individuals with special needs, using ICT tools to accomplish tasks is indeed a relief to their difficulties. Adoption of Information and Communication-based Technology in special education programme will improve the development of special education in Nigeria. 
Special education programme as stipulated in the National Policy on Education (NPE) is "a customized education programme, designed to meet the unique needs of persons with special needs that the general education programme cannot provide" (FRN, 2004). The learning of students with disabilities is concerned with where and how the curriculum is delivered or accessed. Thus, the provision for an appropriate education programme in the special environment has led to the development of a separate educational system which is designed to take care of the educational needs of individuals with special needs.

Today, the teaching and learning of individuals with special needs is one area of education that is attracting a universal concern and great pull of technologies towards its enhancement and efficiency. Special education technologies are those technologies that are provided to enhance functional capabilities and encourage individuals with special needs participation in education, thereby helping them to improve their academic achievement (An, Sharif, Wong, \& Marriappan, 2014). Integrating emerging technologies into special education will not only offer help but increase the opportunities for students with special needs to meeting their educational aspirations.

Individuals with disabilities include all persons who have long-time physical, mental, emotional, or sensory impairments, whose interaction with the different attitudinal and environmental barriers prevent them from full and or effective performance within the society on an equal basis with others (Convention on the Rights of Persons with Disabilities, 2016). Physical disability is just a segment of individuals with disabilities. It has to do with abnormality or loss of function in a person's physical structure. Physical disability brings a limitation on a person's physical fitness, functionality, mobility, and skills (WHO, 2015). Physical disability whether partial or total loss of ability reduces the ability of the learner to learn freely. Visual impairment, speech impairment, hearing impairment, and mobility limitation are the most common physical disabilities found in special needs schools in Nigeria (Adebisi, 2014).

Students with physical disabilities usually experience difficulties with writing, reading, vision, reception of information and gripping objects like pen/pencil or moving arms or legs in full motion. It has become quite clear that these students cannot learn freely without the support of technology. United Nations International Children's Emergency Fund and World Health Organization joint report (UNICEF \& WHO, 2015) acclaimed the need for the implementation of modern assistive technology to support them in their functional deficits and to assist them access instruction and thus learn better.

Assistive technology (AT) is an umbrella term which is made up of assistive, adaptive, rehabilitative technologies and related services which are specifically made or adapted to serve as technical assistance for students and professionals with disabilities. In this case, special education teachers and support staff (An, et al., 2014). Assistive technology involves the application of technologies that can assist in the teaching and learning process of students with disabilities and they widely differ in quality and effectiveness. Some assistive technologies are used to provide individuals with disabilities with educational opportunities while bringing out the cognitive potential in them, while some are used to enable the curricula and teachers to achieve their objectives, while the students are active participants in the learning process. Assistive technologies used in the education process of individuals with disabilities have been grouped in various ways in the special education literature. Nsofor and Bello (2015) grouped assistive technology into low technologies, medium technologies and high technologies.

Low technologies (low-tech), are the common and inexpensive devices and tools purposively designed or adapted to assist in different areas of difficulties. They include simple pencil-grips, magnificent eyeglasses, and large-print cardholder to mention but the few. However, 
researchers have noticed that with the current technological advancement, low-tech AT is becoming more of a crutch than academic support tools (Rowlands, 2015). Medium technologies (Mid-Tech) are the simple electronic devices (sometimes battery operated) and some relatively complicated mechanical devices like a wheelchair, audiotape recorder, and ordinary calculator among others (Nsofor et al., 2015). Like the low-tech, findings of earlier researches within the special education ecosystem also indicated that these technologies cannot fully support student-centred learning. Therefore, there is a need to incorporate high technologies into classroom teaching and learning. High technologies (High-Tech) include advanced electronic and computerized devices. It involves the use of hardware and software that convert speech to text and text to speech, portable dictionary, spelling checker, and reading pen among others (Nsofor et al., 2015).

Special education teachers are faced with different challenges of attending to the diverse learning needs of students with physical disabilities in the classrooms. While some of these students cannot read a print document, others experienced difficulty receiving spoken information. To others, communication is the greatest challenge they face while at the sametime, the movement to classrooms is the greatest challenge others face. Teachers' role in special education is consistent and significant to students' progress. Consequently, educationists have been working tirelessly to ensure that these students access learning in ways that take care of their learning differences. This involves the use of assistive technologies in planning instruction, classroom presentation and assessment. Furthermore, the potential of high-tech assistive technologies for students with special needs is likely to be found not in the technologies themselves but in the way these technologies are used by the teachers and students as teaching and learning tools. Onivehu, Ohawuiro, and Oyeniran (2017), opined that the extent of use of assistive technologies in the classroom is determined by the attitude, experience and quality of teachers. This will require both teachers and students to get familiar with assistive devices and software available in their schools which they can use to provide needed accommodation, substitution, modifications, adjustment, and adaptations that will help special needs students to access environment, curriculum, instruction, or assessment practices. Thus, the use of assistive technology within the special education ecosystem cannot be underestimated (Shikden, 2015).

Across the developing countries, research findings show that there is a high degree of underuse and sometimes abandonment of assistive technology devices. In his finding Coleman (2011) has discovered several unused assistive technology devices kept on shelves or stored in schools' cabinets. He has also discovered the ineffective use of the devices from both teachers and students. Special education teachers sometimes displayed high rate of anxiety in the use of assistive technology in the classroom, especially where these devices are newly introduced (Shikden, 2015). Perhaps, the likely reasons behind that dilemma may not be too far from the lack of consistency in use of assistive technology devices in the classroom and teachers' lack of training and experience on how best they can use technology in the classroom. Furthermore, many students with disabilities, teachers, and as well as their families have limited knowledge of assistive technologies (WHO, 2016), which has made it difficult for them to identify and use these technologies for the benefit of the disabled students.

Lack of training has been considered as one of the reasons leading to the underused and possible abandonment of assistive technology devices, especially among teachers and students with disabilities. Coleman (2011) reported that most teachers and other support staff do not receive adequate training on how to operate modern high-tech assistive technologies. Also identified as one of the major barriers to providing AT services in schools, is lack of funding. Allocation of sufficient funds for the educational sector and ICT development does not seem to be very 
attractive to the leaders in most developing countries like Nigeria. This can be seen from the budgetary allocations among the developing countries where greater allocations of the budget often go for the defence rather than education (El-Rufai, 2011). In addition, a global survey on government of 114 countries action on the implementation of the standard rules on the equalization of opportunities for person with disabilities have discovered that $36 \%$ of the countries had not allocated the required fund for developing and supplying assistive technologies to schools (WHO, 2011).

Additionally, in line with the special education schools support recommendations on studentteacher ratio. United Nation Education Scientific and Cultural Organization (UNESCO) institute for statistics recommended 6:1; while the Nigeria National Policy on Special Education (NPSE) recommended 10:1 as students-teacher ratio (UNESCO, 2011; NPSE, 2015). Despite these recommendations, it is quite obvious that the ratio of students-teacher in special schools remained high in Nigeria (Omede, 2016). High students-teacher ratio narrows down the opportunities for the disabled students to receive adequate attention from teachers and care givers. This may lead to underutilization of assistive technology device attached to the students.

Notwithstanding, the situation is expected to be different nowadays since there is growing concern regarding the provision and use of assistive technology in Nigeria. Both government and non-governmental organizations have shown renewed interest especially with the call for better education service delivery for all. Hence, teachers need to be aware of what exists within the school realm, and how they can perceive the use of these assistive devices and step forward in ensuring effective teaching and learning within the classroom.

Thus, the need to investigate teachers' perceptions is crucial in determining the extent of use of high-tech assistive resources (Onivehu, Ohawuiro, \& Oyeniran, 2017). In essence, when teachers perceived the use of high-tech devices like Dragon speak (software that converts speech-to-text) as good for students who have trouble with listening to spoken words or Word Q (software that converts text-to-speech) as useful for the visually impaired students they will be motivated to facilitate the use in the classroom.

\section{Statement of the Research Problem}

The emphasis of education today is that teaching and learning should be student-centred. However, this is almost impossible for students with special needs. How teachers teach and learners access curriculum is crucial for the attainment of these current educational demands. For students with physical disabilities, access to the curriculum will require the use of assistive technologies. Research findings in the field of special education showed that despite the adoption of traditional technologies, many of the students with disabilities in developing countries like Nigeria are still experiencing barriers in learning, as they continue to learn under frustrating conditions. These include difficulties in reading, writing and reception of information. This causes drop out of many physically challenged students from school for the option of street begging; a phenomenon that is quite worrisome in Nigeria, most especially in this region of the country under study. Furthermore, the very few who manage to graduate from school certainly do so without necessary skills for survival and as such, they found it difficult to be absorbed by today's labour market. Additionally, the few that were lucky to be employed on condition of their status find it difficult to perform on the job because they weren't adequately trained using assistive technologies. Therefore, using low technologies is not enough to meet the needs of people with disabilities effectively. High-Tech assistive options are indeed required to offer the best way of assistance to individuals with disabilities to succeed in the classroom, in the community, and in the workplace. While there is a need for high-tech AT resources there is also 
the need to undertake studies to see into the development and use of high-tech assistive technology for teaching and learning of students in special education schools. Thus, it is this gap in research and development that prompted the researchers to undertake an investigation into teachers' perceptions and factors limiting the use of high-tech assistive technology in special education schools in north-west Nigeria.

\section{Research Questions}

The following are the research questions raise to guide this study:

1. How often do teachers use assistive device(s) or software when teaching students with physical disabilities in special education schools in North-West Nigeria?

2. What are the perceptions of teachers towards the use of high-tech assistive technology resources in teaching and learning of students with physical disabilities in special education schools in North-West Nigeria?

3. What are the major factors that are preventing teachers from effective utilization of high-tech assistive devices in teaching the physically challenged students in special education schools in North-West Nigeria?

\section{METHODOLOGY}

The research design adopted for this study is descriptive survey research. This is because the designed made it possible for the researchers to have a broad view from a sample of special education teachers in the special education schools in order to draw conclusions regarding hightech assistive technology resources utilization in special education schools in Nigeria.

\section{Population and Sample}

The population for this study include all three hundred and fifty-four (354) teachers of special education schools in North-West Nigeria. The target population for this study comprised of one hundred and twenty (120) special education teachers from comprehensive special education schools in North-West Nigeria. The study adopted a multi-stage sampling technique in selecting the sampled schools and the respondents.

\section{Instrument}

A questionnaire was used to collect the required information for the study. It was subjected to expert assessment in order to determine their face and content validity. Two lecturers from the Department of Educational Technology, Federal University of Technology, Minna, and two special education lecturers from Niger State College of Education, Minna validated the comprehensiveness, adequacy and clarity of the items. Corrections and suggestions raised by these experts were incorporated in the final drafted questionnaire. The reliability of the instrument used was established through pilot testing with 20 teachers from two special education schools within the study area, but not part of the sampled schools. The reliability value of 0.81 was obtained for the questionnaire using the Cronbach Alpha formula. The data collected was analysed using descriptive statistics such as percentage, mean and standard deviation. 


\section{RESEARCH FINDINGS}

Research Question 1: Findings on how often teachers use assistive device(s) or software when teaching students with physical disabilities in special education schools in North-West Nigeria.

Table 1. Frequency and Percentage of Teachers' Responses on the Use of High-Tech Assistive Technology Resources

\begin{tabular}{|c|c|c|c|c|c|c|c|c|c|c|c|}
\hline \multirow{2}{*}{\multicolumn{2}{|c|}{ SN Items }} & \multicolumn{2}{|c|}{ A } & \multicolumn{2}{|c|}{$S$} & \multicolumn{2}{|c|}{$\mathbf{R}$} & \multicolumn{2}{|c|}{0} & \multicolumn{2}{|c|}{ NA } \\
\hline & & No. & $\%$ & No. & $\%$ & No. & $\%$ & No. & $\%$ & No. & $\%$ \\
\hline $\mathrm{i}$ & $\begin{array}{l}\text { I use high-tech assistive device(s) / } \\
\text { software to facilitate teaching and learning } \\
\text { in the classroom. }\end{array}$ & 7 & 5.8 & 27 & 22.5 & 42 & 35 & 32 & 26.7 & 12 & 10 \\
\hline ii & $\begin{array}{l}\text { I use high-tech assistive device(s) / } \\
\text { software to actively engage the physically } \\
\text { challenged students in the classroom. }\end{array}$ & 5 & 4.2 & 28 & 23.3 & 37 & 30.8 & 39 & 32.5 & 11 & 9.2 \\
\hline iii & $\begin{array}{l}\text { I use high-tech assistive device(s) / } \\
\text { software to assess the physically } \\
\text { challenged students in the classroom. }\end{array}$ & 9 & 7.5 & 23 & 19.2 & 38 & 31.7 & 21 & 17.5 & 29 & 24.1 \\
\hline iv & $\begin{array}{l}\text { I use high-tech assistive device(s) / } \\
\text { software to generate teaching aids for } \\
\text { classroom presentation. }\end{array}$ & 2 & 1.7 & 15 & 12.5 & 34 & 28.3 & 22 & 18.3 & 47 & 39.2 \\
\hline v & $\begin{array}{l}\text { I use high-tech assistive device(s) / } \\
\text { software to enhance physically challenged } \\
\text { students' participation in the classroom. }\end{array}$ & 5 & 4.2 & 10 & 8.3 & 29 & 24.2 & 46 & 38.3 & 30 & 25 \\
\hline
\end{tabular}

Table 1 shows the results of teachers' responses regarding the use of assistive resources in special education schools. Specifically, item one has a frequency and percentage scores of 7 (5.8\%), 27 (22.5\%), 42 (35\%), 32 (26.7\%) and 12 (10\%) for Always, Sometimes, Rarely, Once and Not at all, respectively which indicated that majority of the teachers rarely used assistive devices to facilitate teaching and learning in the classroom. Similarly, item 2 has a frequency and percentage scores of 5 (4.2\%), 28 (23.3\%), 37 (30.8\%), 39 (32.5\%) and 11 (9.2\%) for Always, Sometimes, Rarely, Once and Not at all, respectively which showed that majority of the teachers only used assistive devices to actively engage students with physical disabilities in the classroom once. On the other hand, Item three has a frequency and percentage scores of $9(7.5 \%), 23$ (19.2\%), 38 (31.7\%), 21 (17.5\%) and 29 (24.1\%) for Always, Sometimes, Rarely, Once and Not at all, respectively which meant that most of the teachers rarely used assistive devices to assess students with physical disabilities in the classroom. Also, item four has a frequency and percentage scores of 2 (1.7\%), 15 (12.5\%), 34 (28.3\%), 22 (18.3\%) and 47 (39.2\%) for Always, Sometimes, Rarely, Once and Not at all, respectively which indicated that most teachers never used assistive devices to generate teaching aids for classroom presentation. Furthermore, item five has a frequency and percentage scores of $5(4.2 \%), 10(8.3 \%), 29(24.2 \%), 46(38.3 \%)$ and 30 (25\%) for Always, Sometimes, Rarely, Once and Not at all, respectively which showed that many teachers used high-tech assistive devices to enhance students with physical disabilities' participation in the classroom only once. On a general note, it can be deduced from the results presented in Table 1 that most of the respondents do not regularly make use of high-tech assistive devices and software in teaching students with physical disabilities in special education schools. Most of the responses were concentrated between sometimes, rarely and once, except for item four were most the teachers reported that they have never used high-tech assistive technologies to generate instructional materials.

Research Question 2: Findings on perceptions of teachers towards the use of high-tech assistive technology resources in teaching and learning of students with physical disabilities in special education schools in North-West Nigeria. 
Table 2. Mean and Standard Deviation on Teachers perceptions on the Use of High-Tech Assistive resources in Teaching and Learning of Students with Physical Disabilities

\begin{tabular}{lcccc}
\hline SN Items & $\mathbf{N}$ & $\overline{\boldsymbol{X}}$ & SD & Decision \\
\hline $\begin{array}{l}\text { The use of high-tech assistive device(s)/software will enhance } \\
\text { teachers classroom presentation }\end{array}$ & 120 & 3.9 & 1.08 & Agree \\
\hline $\begin{array}{l}\text { The use of high-tech assistive device(s)/software will help teachers } \\
\text { to provide instruction in a purposive way to take care of students' } \\
\text { diverse needs in the classroom. }\end{array}$ & 120 & 3.6 & 1.18 & Agree \\
\hline $\begin{array}{l}\text { The use of high-tech assistive device(s)/software will help teachers } \\
\text { iii to develop lessons that will actively engage students with physical } \\
\text { disabilities in the classroom. }\end{array}$ & 120 & 3.7 & 1.24 & Agree \\
\hline $\begin{array}{l}\text { The use of high-tech assistive device(s)/software will help students } \\
\text { with physically disabilities to access curriculum better. }\end{array}$ & 120 & 3.6 & 1.18 & Agree \\
\hline $\begin{array}{l}\text { The use of assistive device(s)/software will encourage participation } \\
\text { of students with physical disabilities in the classroom. }\end{array}$ & 120 & 3.5 & 1.22 & Agree \\
\hline Grand Mean & 3.7 & & Agree \\
\hline
\end{tabular}

Decision Mean = 3.0

The result in Table 2 revealed that teachers appreciate the added values of high-tech assistive technologies, when referring to classroom presentation, addressing students' diverse needs in the classroom, development of lessons that will actively engage the students, helping students to access curriculum much better and enhancing students' participation in classroom activities. These are all significant benefits of these new teaching and learning technologies. This is shown in the summary of the table which reveals the grand mean score of 3.7 greater than the decision mean score of 3.0.

Research Question 3: Findings on the major factors that are preventing teachers from effective utilization of high-tech assistive devices in teaching the physically challenged students in special education schools in North-West Nigeria.

Table 3. Mean and Standard Deviation on Factors Limiting the Use of High-Tech Assistive Resources in Special Education Schools

\begin{tabular}{|c|c|c|c|c|}
\hline SN Items & $\mathbf{N}$ & $\overline{\boldsymbol{X}}$ & SD & Decision \\
\hline $\begin{array}{l}\text { i Inadequacy of assistive devices and software limits their use in the } \\
\text { classroom }\end{array}$ & 120 & 3.4 & 1.37 & Agree \\
\hline $\begin{array}{l}\text { in Inadequate electricity supply reduces the use of assistive devices } \\
\text { and software in the classroom }\end{array}$ & 120 & 3.6 & 1.24 & Agree \\
\hline $\begin{array}{l}\text { Poor classroom setting hinders the use of assistive devices in the } \\
\text { classroom }\end{array}$ & 120 & 3.9 & 1.08 & Agree \\
\hline $\begin{array}{l}\text { Lack of awareness of the existence of assistive devices in schools } \\
\text { hinders their use }\end{array}$ & 120 & 3.9 & 1.08 & Agree \\
\hline $\begin{array}{l}\text { Lack of training reduces the use of assistive devices/software in the } \\
\text { classroom }\end{array}$ & 120 & 3.8 & 1.17 & Agree \\
\hline $\begin{array}{l}\text { Lack of motivation reduces the use of assistive devices in the } \\
\text { classroom }\end{array}$ & 120 & 3.3 & 1.40 & Agree \\
\hline vii Lack of awareness hinder the use of assistive devices & 120 & 3.7 & 1.33 & Agree \\
\hline viii Poor teachers' attitude hinder the use of assistive devices & 120 & 3.8 & 1.17 & Agree \\
\hline $\begin{array}{l}\text { ix Lack of competency reduces the use of assistive devices in the } \\
\text { classroom }\end{array}$ & 120 & 3.5 & 1.21 & Agree \\
\hline Grand Mean & & 3.7 & & Agree \\
\hline
\end{tabular}

Decision Mean $=3.0$

The results of the analysis of Table $\mathbf{3}$ showed some problems pointed out by the teachers as hindrances to assistive technology implementation in the classroom. With the mean score of 3.4 and a standard deviation of 1.37 for item one, teachers' stated that "inadequacy of assistive 
devices limits their use in the classroom". Also, teachers stated that "inadequate electricity supply reduces the use of assistive devices in the classroom". This is represented with the mean score of 3.6 with a standard deviation of 1.24. Teachers were unanimous in their report regarding items three and four with mean scores of 3.9 and standard deviation of 1.8, which states that "poor classroom setting and lack of awareness on the existence of assistive devices" reduces assistive technology devices used in the classroom. In the same manner, teachers believe that "lack of training reduces the use of assistive devices in the classroom" with the mean score 3.8 with a standard deviation of 1.17. Furthermore, teachers' responses regarding item six which states that "Lack of motivation reduces the use of assistive devices in the classroom" is equally high with the mean score of 3.3 and standard deviation of 1.40. Teachers' responses towards item seven which states that "Lack of awareness hinder the use of assistive devices" was also high with a mean score of 3.7 and a standard deviation of 1.33. Similarly, item eight which states that "Poor teachers' attitude hinders the use of assistive devices" receives a high mean score of 3.8 and a standard deviation of 1.17. Finally, item nine which states that "Lack of competency reduces the use of assistive devices in the classroom" has a mean score of 3.5 and standard deviation of 1.21. On a general note, the results of Table 3 reveal the grand mean score of 3.7 which is greater than the decision mean score of 3.0. This implies to a greater extent that the factors identified significantly hindered teachers from the use of assistive devices in special education schools.

\section{DISCUSSION OF FINDINGS}

The aim of this research is to assess teachers' perceptions of high-tech assistive technology resources utilization in special education schools in North-West Nigeria. In line with this, three research questions were formulated, responses generated were analysed using frequency count, percentage, mean and standard deviation and results were presented in Table 1, 2, and 3, respectively. As shown in the results for the first research question, responses that emanated from the assessment on the extent to which teachers make use of assistive devices available in special education schools was based on five different items. Unfortunately, the finding revealed that most special education teachers do not regularly make use of assistive devices and software in teaching students with physical disabilities. This may be due to insufficiency of these resources, and perhaps lack of adequate training and poor motivation of teachers. This finding is in agreement with the finding of Maraizu (2014) which maintained that most special education coordinators surveyed in Enugu state - Nigeria, reported that teachers do not regularly use technology to teach because of the insufficiency in the supply of assistive resources to special education schools. This is indeed alarming considering the significance of technology to the teaching and learning of students with disabilities. Also, this finding agreed with the finding of Onivehu, Ohawuiro, and Oyeniran (2017) which discovered that teachers of students with physical disabilities were not using assistive devices to teach because of their high-tech nature and because they were not adequately available and accessible by teachers.

Teachers' perception of the extent to which the use of assistive devices and software can improve the teaching and learning of students with physical disabilities was also covered in this study. Finding regarding this area of the study revealed that the use of high-tech assistive devices to deliver instruction will improve teaching and learning in special education schools. This will help to relief teachers the stress of having to attend to the needs of every student in the classroom. This finding corroborates with the finding of Ajuwon and Chitiyo (2015) which discovered that the use of the necessary assistive technology in special education schools in Nigeria will not only provide support to students with special needs but also improves teachers and students' performance in the classroom. 
Another finding that aroused from this study also revealed some major factors that hindered teachers in special education schools in North-West Nigeria from frequent use of high-tech assistive resources to support classroom presentation. The finding revealed problems that include inadequacy of assistive devices, inadequacy of power supply, poor classroom setting, lack of training and lack of knowledge of these assistive devices, lack of motivation, lack of competency in using these devices and poor teachers' attitude as major barriers to the use of assistive devices by teachers in special education school within the region under study. This finding corroborates with the finding of Shikden (2015) which found out teachers lack of competency in using assistive technology, insufficiency of assistive technologies and lack of regular electricity supply were among the major factors that hindered the effective use of assistive devices in special education schools in North Central Nigeria. Similarly, this finding is also in line with the finding of Ajuwon and Chitiyo (2015) which discovered that lack of training in the use of assistive devices, lack of appropriate assistive devices and services in the classroom and irregular electricity supply are the biggest challenges regarding assistive technology utilization in special education schools in Nigeria.

\section{CONCLUSION}

Based on the findings from the analysis of the data collected for this study, the researchers concludes that high-tech assistive devices and software that are necessary for quality teaching and learning in special education schools across North West Nigeria were perceived to be potential for quality special education delivery. The study also concluded that although special education teachers perceived that the use of high-tech assistive resources is significant for quality special education delivery, special education teachers do not regularly make use of the available high-tech assistive resources in teaching students with physical disabilities in special education schools. The study discovered inadequacy of assistive devices, poor funding of special education and lack of regular supply of assistive technology by the government, inadequacy of power supply, poor classroom setting, lack of knowledge of high-tech assistive devices, lack of motivation, lack of competency in using these devices and poor teachers' attitude as major barriers to the use of assistive devices by teachers in special education school within the region under study.

It can be concluded that the use of assistive technology in special education schools can facilitate effective teaching and learning of students with disabilities, implementing the emerging assistive technology in the classroom will require a radical shift from traditional teacher-based pedagogical approach to a pedagogy that is student-centred. Teaching and learning with hightech assistive devices will besides making this enterprise not only interesting but also meaningful so as to enhance the productivity of both the special education teachers and students.

\section{RECOMMENDATIONS}

Based on the findings of this study, the following recommendations were given:

1. Government and other stakeholders should organize workshop, seminars and other capacity building training regularly for teachers as means of updating their knowledge and skills in the use of assistive devices considering the dynamic nature of special education technology.

2. Special education teacher training institutions should include assistive technology in their preparatory programme that will equip pre-service teachers with the necessary knowledge and skills that will ensure a minimum level of competence in the classroom. 
3. Curriculum planners should see these assistive devices beyond just the high-tech they are, but life-changing technologies that can bring improvement in the way teachers teach and learners learn. Hence, the need to incorporate them in planning curriculum and pedagogy for students with special needs.

\section{REFERENCES}

Adebisi, R. O. (2014). Using information and communication technology in teaching children with special needs in $21^{\text {st }}$ century. JRSTME: Journal of Research in Science, Technology and Mathematics Education, 2(1), 129-138.

Ajuwon, P. M., \& Chitiyo, G. (2016). Survey of the use of assistive technology in schools in Enugu. Journal of the International Association of Special Education, 1, 4-13.

An, F., Sharif, S., Wong, W. K., \& Marriappan, M. (2014). Innovation of assistive technologies in special education: A review. IJERED: International Journal of Enhanced Research in Educational Development, 2(3), 25-38. Retrieved from www.erpublications.com.

Coleman, M. (2011). Successful implementation of assistive technology to promote access to curriculum and instruction for students with physical disabilities. Journal of Assistive Technology and Physical Disabilities, 22(3), 2-22.

El-Rufai, N. (2011, July 29). Why education can't wait? This Day Newspaper. Retrieved from http://www.thisdaylive.com/articles/why-education-cant-t-wait/95888/

Federal Republic of Nigeria (2004). National Policy on Education ( $4^{\text {th }}$ edition). Abuja: NERDC

Federal Republic of Nigeria (2015). National Policy on Special Education. Abuja: NERDC

Maraizu, U. S. (2014). An assessment of assistive technology devices and services used at secondary school level in an urban Enugu, Nigeria, public school district. A published Ph.D Dissertation of Capella University. Retrieved from http://eric.ed.gov/?id=ED567248.

Nsofor, C. C., \& Bello, A. (2015). Emerging trends in educational technology. Ibadan: Emmi Pres.

Omede, A. A. (2016). Assessment of special education service delivery: A global perspective. British Journal of Psychology Research, 4 (2), 43-53.

Onivehu, A. O., Ohawuiro O. E., \& Oyeniran B. J. (2017). Teachers' attitude and competence in the use of assistive technologies in special needs schools. Acts Didactica Napocensia, 10(4), 21-32. https://doi.org/10.24193/adn.10.4.3

Rowlands, T. (2015). The utilisation of assistive Technology to enhance education support for all learners in a mainstream school (PhD Thesis), University of South Africa.

Shikden, A. G. (2015). A survey of teachers' awareness and use of assistive technology in teaching children with special needs in north central Nigeria (Unpublished Thesis), Department of special education and rehabilitation sciences, Faculty of Education, University of Jos, Plateau State, Nigeria.

UNICEF \& WHO (2015). Assistive technology for children with disabilities: Creating opportunities for education, inclusion and participation. A discussion paper. Retrieved from http://www.unesdoc.unesco.org/disabilities 
CONTEMPORARY EDUCATIONAL TECHNOLOGY, 2020, 11(1), 99-109

DOI: https://doi.org/10.30935/cet.646841 - TYPE: Research Article

United Nation (2016). Convention on the rights of persons with disabilities (CRPD). New York: United Nations.

Word Health Organization (2011). World report on disability. Geneva: WHO. Retrieved from www.who.un.org

Word Health Organization (2016). Priority assistive products list. Geneva: WHO. Retrieved from www.who.un.org

Correspondence: Emeka Joshua Chukwuemeka, Department of Educational Technology Federal University of Technology, Minna, Niger State, Nigeria. E-mail: emekac.joshua@gmail.com 